Original Article

\title{
PREVALENCE AND RISK FACTORS OF ESSENTIAL HYPERTENSION AND NEW ONSET OF DIABETES IN ESSENTIAL HYPERTENSION IN RURAL POPULATION OF HARYANA
}

\author{
VIKAS JHAWATa, SUMEET GUPTA ${ }^{a}$, BIMAL K. AGARWAL ${ }^{\mathrm{b}}$, PARTHA ROYc, VIPIN SAINI ${ }^{\mathrm{a}}$
}

aDepartment of Pharmacology, M. M. College of Pharmacy, M. M. University, Mullana, (Ambala), Haryana, India, bDepartment of Medicine, M. M. Institute of Medical Sciences and Research, M. M. University, Mullana, (Ambala), Haryana, India, cDepartment of Biotechnology, Indian Institute of Technology Roorkee, Uttarakhand Email: sumeetgupta25@gmail.com

Received: 22 Nov 2017 Revised and Accepted: 03 Jan 2018

\begin{abstract}
Objective: We conducted a well-designed prevalence study in a rural population of Haryana in Mullana rural area to find out the latest prevalence of essential hypertension, the prescription pattern of antihypertensive drugs and the associated risk of new onset of diabetes.

Methods: A retrospective study was carried out on the patient data (2672 patients) from the years 2009 to 2013 at OPD of M. M. University hospital, Mullana to find the previous year's prevalence of different diseases, including essential hypertension, new onset of diabetes and associated risk factors, prescription pattern of antihypertensive drug therapy. Based on the above results, a prospective study was conducted from January 2015 to December 2016 and total 510 patients (270 essential hypertension and 240 essential hypertension with new onset of diabetes) and 270 normal individuals were recruited in the study.
\end{abstract}

Results: The retrospective study, a total of 2672 patients' data was evaluated which showed $41.21 \%$ prevalence of essential hypertension, $11.83 \%$ new onset of diabetes in Essential hypertension patients and 15.87\% diabetic patients. Antihypertensive monotherapy was prescribed to $59.85 \%$ patients and combination therapy to $40.15 \%$ patients while that of a prospective study showed $40.37 \%$ patients of monotherapy and $59.63 \%$ patients of combination therapy. The prospective study also showed that different anthropometric parameters were significantly associated with risk of hypertension and new onset of diabetes except for age and height.

Conclusion: An increase in the prevalence of essential hypertension and associated risk factors was observed when compared with previous studies and retrospective study. It is clearly seen by the change in drug therapy pattern and different anthropometric parameters. Implementation of a large scale awareness program is needed to combat these metabolic diseases.

Keywords: Anthropometric Parameters, Antihypertensive Therapy, Essential Hypertension, New Onset of Diabetes, Prevalence Study, Rural Area

(c) 2018 The Authors. Published by Innovare Academic Sciences Pvt Ltd. This is an open access article under the CC BY license (http://creativecommons.org/licenses/by/4.0/) DOI: http://dx.doi.org/10.22159/ijpps.2018v10i2.23891

\section{INTRODUCTION}

Chronic diseases like hypertension and diabetes mellitus are prevailing at an epidemic scale throughout the world due to continuous chronic change in the lifestyle pattern of mankind, which then further lead to high mortality rates $[1,2]$. Even in India, hypertension affected $25 \%$ of urban and $33 \%$ of rural populations. The data suggested that among the essential hypertension affected population, only $38 \%$ of urban and $25 \%$ of the rural population are being treated for hypertension [3]. By the year 2025, the global load of hypertension is expected to increase from 1 billion to 1.56 billion, which will further worsen the conditions [4]. Hypertension alone is considered as the risk factor for many cardiovascular diseases, including new onset of diabetes. Many studies found a close association of essential hypertension with diabetes mellitus as both share a common metabolic pathway and also both affect the pathophysiology of one another $[5,6]$. Around one-third hypertensive patients are reported to develop diabetes in later stages of hypertension [7]. Co-existence of hypertension and diabetes at a single time in an individual is $75 \%$ more dangerous than either a single disease which increases the risk of another cardiovascular disease such as coronary heart disease, nephropathy, retinopathy and stroke $[8,9]$. In addition, certain antihypertensive therapies (especially beta-blockers (BBs), diuretics, angiotensinconverting enzyme inhibitors (ACEIs) and calcium channel blockers (CCBs)) on prolonged use (for $3 \mathrm{y}$ or more) are also reported to induce type 2 diabetes or glucose dysregulation in hypertensive patients under the influence of polymorphic alleles of certain genes [10]. Even it is very hard to control hypertension in patients who have developed diabetes and a combination of antihypertensive therapies is needed to take control over high blood pressure [11].
This may further complicate the situation of glycemic dysregulation due to excessive use of antihypertensive drugs. Hence, it is better to diagnose and treat diabetes in hypertensive patients at an early stage to avoid such complications. Therefore, identification of the type of hypertensive patients (based on certain clinical markers, genetic markers ethnic markers and certain other markers) who are more prone to develop diabetes may also help to combat metabolic complexities and reduce the mortality associated with these diseases.

Haryana is a northern state of India with people from diverse ethnic and cultural groups. An earlier study (in 2011) found a higher (38.2\%) prevalence of hypertension (59.2\% males and $40.8 \%$ females) in a rural population of Haryana [12]. Therefore, in the present study, we tried to find out the current prevalence of different diseases, including hypertension, diabetes mellitus and new onset of diabetes in hypertensive patients along with the different drug therapies in the same rural population of this area.

\section{MATERIALS AND METHODS}

Ethics

The study was approved (IEC/670) by the Institutional Ethics Committee of M. M. University and a prior written consent was obtained from all the participants.

\section{Study design}

The present study was carried out on the 38,500 inhabitants residing in a 30-kilometer radius of Mullana block in the Ambala district of Haryana State. A retrospective analysis (on the previous year's patient data) was done to find out the previous five years data 
on the prevalence of different diseases, including essential hypertension and Essential hypertension with new onset of diabetes and a prospective study was conducted to assess the risk factors associated with essential hypertension and new onset of diabetes in these patients. The detailed study design is discussed as given below:

\section{Retrospective study}

The retrospective study was conducted in M. M. Institute of Medical Science and Research, Mullana (Haryana) on total 2672 patients visiting the OPD of the hospital during the years from 2009 to 2013. The retrospective data were collected from the patient data center of the university hospital to find out the prevalence of different diseases, including essential hypertension and essential hypertension with new onset of diabetes in this rural population.

\section{Prospective study}

The data from our retrospective study suggested that a sufficient number of patients are available within the hospital to conduct a prospective study on the same area population to assess the risk factors associated with essential hypertension and the associated new onset of diabetes. The prospective study was conducted on patients visiting the medicine OPD of a university hospital from January 2015 to December 2016. A sample size of 164 patients would be sufficient to represent the essential hypertension population residing in the rural area under investigation with a power of $80 \%$ and a $P$-value of 0.05 . We have selected 510 patients (270 essential hypertension patients and 240 essential hypertension with new onset of diabetes patients) who visited regularly in hospital OPD. Patients who agree to participate were explained the nature and the objectives of the study and informed consent were obtained individually. In order to make a comparison with normal individuals, we have selected normal individuals with age and sexmatched from the same place and denoted as a normotensive group.

\section{Data collection}

Various parameters like age, sex, body mass index (BMI), height, weight, waist circumference (WC), hip circumference (HC), systolic blood pressure (SBP), diastolic blood pressure (DBP), fasting blood glucose level (FBG), W/H ratio, education, and family history were recorded in a given questionnaire only after taking the patient consent. The information about patient's identity was not included with other data and the only physician had the access to this information.

\section{Inclusion criteria}

The below-given selection criteria were followed and essential hypertension patients of both sexes between the age group of 18 to 75 y were included in the study. Patients on treatment with selective antihypertensive medication (diuretics, BBs, CCBs) for about $3 \mathrm{y}$ or more either as monotherapy and combination therapy (for essential hypertension group), essential hypertension patients with new onset of diabetes patients (as diagnosed by the physician) (for essential hypertension with new onset of diabetes group) and normal individuals without any history of essential hypertension and diabetes and without any drug therapy were included.

\section{Exclusion criteria}

The exclusion criteria indicated that all individuals with the age below $18 \mathrm{y}$ and above $75 \mathrm{y}$, essential hypertension patients who were on antihypertensive drugs other than diuretics, BBs, and CCB, patients with irregular dosing of antihypertensive therapy, patients with secondary cause of hypertension, pregnant and lactating mothers, non-cooperative and disabled patients were also excluded from the study.

\section{Blood pressure measurements}

The blood pressure recordings were taken by the physicians in OPD. An appropriately sized cuff (cuff bladder encircling at least 80 percent of the arm) was used to ensure accuracy in the palpitatory obliteration of radial pulse pressure was obtained before ausculating for blood pressure (BP) measurement. Patients were made to sit quietly for at least $15 \mathrm{~min}$ on a chair and smoking and intake of any kind of drugs (which may affect blood pressure) was avoided for at least $30 \mathrm{~min}$ prior to the BP measurement. Three readings were taken at $5 \mathrm{~min}$ interval, and the average was recorded. By auscultatory method appearance and disappearance of Korotkoff sound were taken as indicative of SBP and DBP, respectively [13].

\section{Blood glucose monitoring}

The FBG level of each recruited patient was monitored to find out the essential hypertension patients with new onset of diabetes after chronic therapy of diuretics, BBs and CCBs.

\section{Statistical analysis}

Data analysis was done with the help of an SPSS version 14.5. Continuous variables were expressed as means ? ? comparisons were made using student t-test. Allele frequencies were calculated from genotype frequencies and were compared using chi-squared $\left(\chi^{2}\right)$ statistics. $P$ value $<0.05$ was considered statistically significant.

\section{RESULTS}

\section{Retrospective study}

Total of 2672 patients was included in the study that consists of $1560(58.38 \%)$ male and $1112(41.62 \%)$ female patients. The prevalence rates of different diseases among male and female populations are given in below table 1.

Table 1: Gender wise prevalence of different disease in the rural population of Haryana during the y 2009 to 2013

\begin{tabular}{|c|c|c|c|}
\hline Disease & Male n (\%) & Female n (\%) & Total n (\%) \\
\hline Essential hypertension & 577 (21.59) & $524(19.61)$ & $1101(41.21)$ \\
\hline Diabetes mellitus & $242(9.06)$ & $182(6.81)$ & $424(15.87)$ \\
\hline Essential hypertension with new onset of diabetes & 122 (4.57) & $194(7.26)$ & $316(11.83)$ \\
\hline Cardiovascular disease & $411(15.38)$ & $150(5.61)$ & $561(21)$ \\
\hline COPD & $175(6.55)$ & $49(1.83)$ & $224(8.38)$ \\
\hline Other diseases & $33(1.24)$ & $13(0.49)$ & $46(1.72)$ \\
\hline Total & $1560(58.38)$ & $1112(41.62)$ & $2672(100)$ \\
\hline
\end{tabular}

$\mathrm{n}(\%)=$ number of total individuals (value in percentage)

From the above table, a very high prevalence of essential hypertension $(41.21 \%)$ was found followed by CVDs $(21 \%)$, diabetes mellitus (15.87\%), essential hypertension with new onset of diabetes $(11.83 \%)$, COPD $(8.38 \%)$ and other non-serious seasonal disease (1.72\%) of the total population (fig. 1).

The male patient population of this rural area showed a high prevalence for both essential hypertension $(21.59 \%)$ and diabetes
(9.06\%) as compared to females (19.61\% and 6.81\% respectively). Essential hypertension with new onset of diabetes was more prevalent in females (7.26\%) than males (4.57\%) among those visited the university hospital. CVDs, COPD and other diseases were more prevalent in male patients as compared to females.

This data showed that female patients were more prone to develop diabetes and hypertension along with their coexistence (fig. 2). 


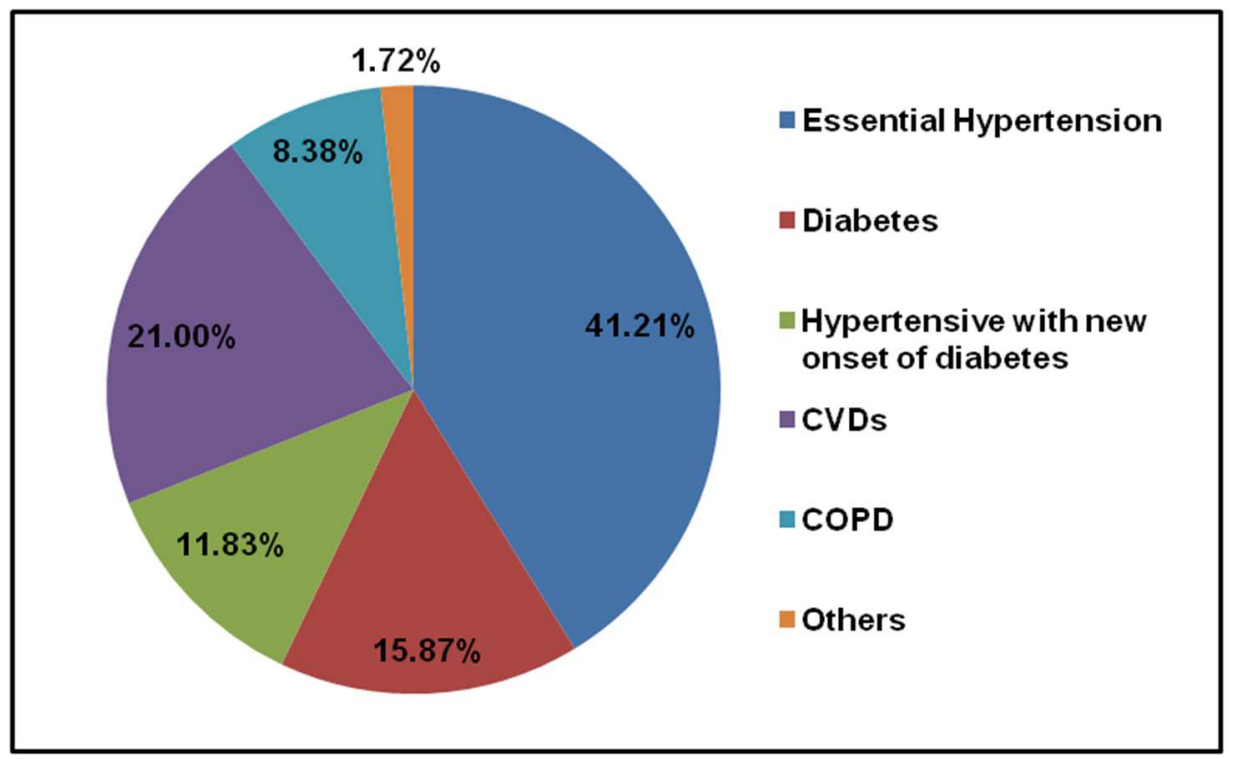

Fig. 1: Prevalence of different disease among the patients visited the medicine OPD of a university hospital from 2009 to 2013

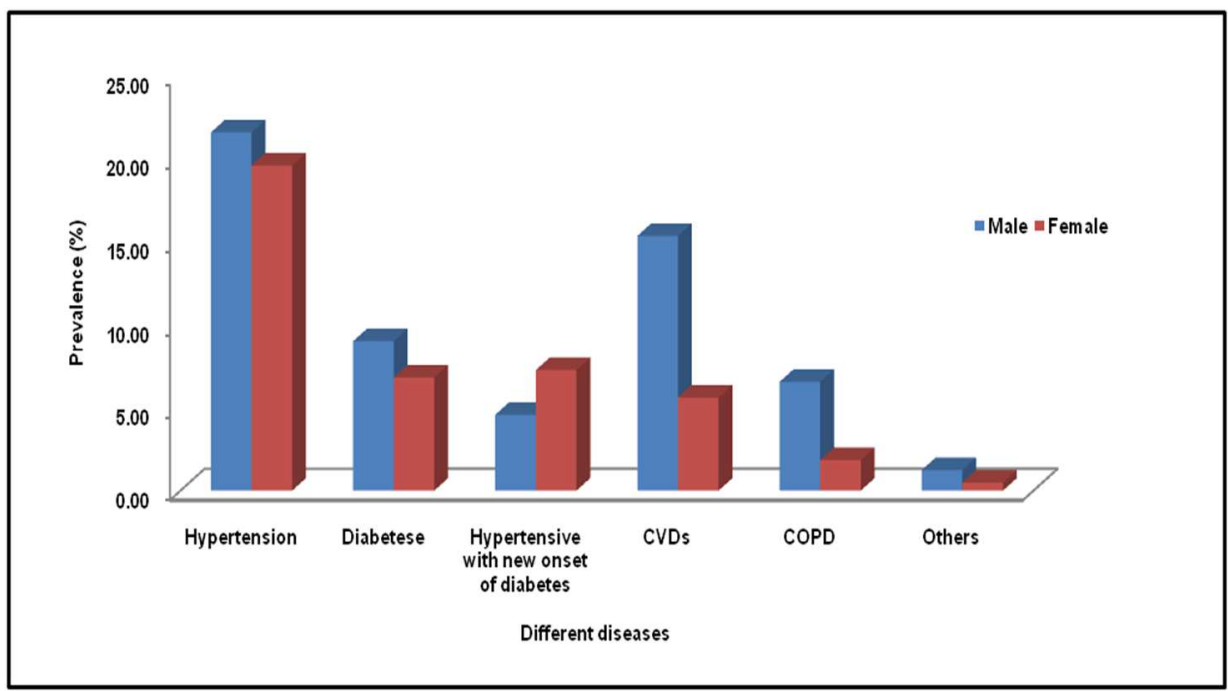

Fig. 2: Gender wise distribution of different diseases among patients visited the university hospital from 2009 to 2013

\section{Antihypertensive therapy prescription pattern}

Out of total 1101 essential hypertension patients, 59.85\% patients were prescribed monotherapy and $40.15 \%$ were prescribed as combination therapy $(24.98 \%$ on the two-drug combination and $15.17 \%$ of multiple drug combination therapy) as given in table 2 .
Gender wise prescription data revealed that the more number of female patients $(30.33 \%)$ were prescribed with antihypertensive monotherapy than male patients $(29.52 \%)$.

However, two drug combinations and multiple drug therapies were more prescribed in males $(14.90 \%$ and $7.99 \%$, respectively) than females $(10.08 \%$ and $7.18 \%$ respectively) (fig. 3 )

Table 2: Prescription pattern of anti-hypertensive therapy among the patients visited the medicine OPD of university hospital from 2009 to 2013

\begin{tabular}{llll}
\hline Pattern & Number of prescriptions & & Total \\
\cline { 2 - 3 } & Male n (\%) & Female n (\%) & $659(59.85)$ \\
\hline $\begin{array}{l}\text { Monotherapy } \\
\text { Combination therapy }\end{array}$ & $325(29.52)$ & $334(30.33)$ & \\
Two drugs & $164(14.90)$ & $111(10.08)$ & $275(24.98)$ \\
Multiple drugs & $88(7.99)$ & $79(7.18)$ & $167(15.17)$ \\
Total & $577(52.41)$ & $524(47.59)$ & $1101(100.00)$ \\
\hline
\end{tabular}

$\mathrm{n}(\%)=$ number of total individuals (value in percentage) 


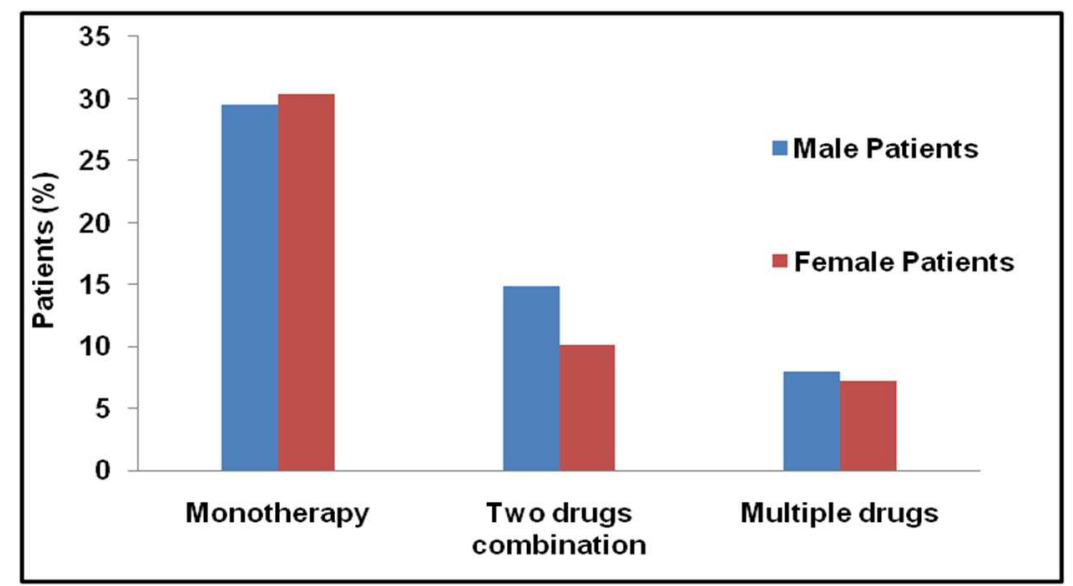

Fig. 3: Gender wise prescription pattern of anti-hypertensive drug therapy

The drug wise data showed that among male patients $28.31 \%$ were prescribed with BBs, 5.54\% with ACEI, $27.08 \%$ with CCB, $12.92 \%$ with diuretics and $26.15 \%$ with ARB. While among female patients $33.23 \%$ were prescribed with BB, $8.68 \%$ with ACEI, $20.06 \%$ with
CCB, $17.66 \%$ with diuretics and $20.36 \%$ with ARB (fig. 4). Data revealed that female patients were most prescribed with BB followed by diuretics and ACEI while male patients were mostly prescribed with CCB followed by ARB.

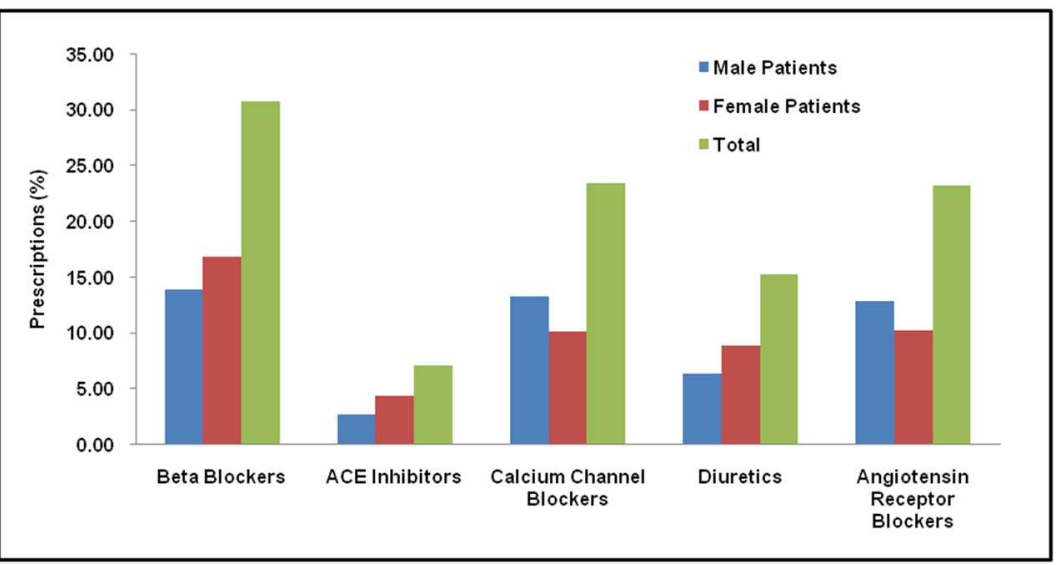

Fig. 4: Gender wise prescription pattern of monotherapy among essential hypertension patients

\section{Prospective study}

Total of 510 patients was recruited for the study and categorized in two groups, i.e. essential hypertension patients $(n=270)$ and essential hypertension with new onset of diabetes patients $(n=240)$. Individuals without any history of hypertension, diabetes, essential hypertension with new onset of diabetes or any other metabolic diseases were selected as normal control $(n=270)$.

Patient information including the history of disease, prescription pattern, anthropometric parameters, BP and FBG level measurements were taken and discussed in below table 3 .

Table 3: Comparative demographic data of normal, essential hypertension and essential hypertension with new onset of diabetes groups

\begin{tabular}{|c|c|c|c|c|}
\hline Parameters & Normal & $\begin{array}{l}\text { Essential } \\
\text { hypertensive }\end{array}$ & $\begin{array}{l}\text { Essential hypertension with new onset of } \\
\text { diabetes }\end{array}$ & $\begin{array}{l}\text { Overall } \\
\text { p-value }\end{array}$ \\
\hline $\mathrm{M} / \mathrm{F}$ & $150 / 120$ & $95 / 175$ & $80 / 160$ & - \\
\hline Age (y) & $51.82 \pm 11.91$ & $53.43 \pm 10.86$ & $54.92 \pm 9.29$ & $0.0054^{\mathrm{a}, \mathrm{c}, \mathrm{ns}, \mathrm{b}, * *}$ \\
\hline SBP (mmHg) & $123.33 \pm 4.99$ & $152.59 \pm 10.24$ & $155.4 \pm 8.17$ & $0.0001^{\mathrm{a}, \mathrm{b}, \mathrm{c}, * * *}$ \\
\hline DBP (mmHg) & $81.51 \pm 3.73$ & $91.80 \pm 2.62$ & $92.31 \pm 2.47$ & $0.0001^{\mathrm{a}, \mathrm{b}, \mathrm{c}, * * *}$ \\
\hline FBG (mg/dl) & $97.18 \pm 6.61$ & $107.20 \pm 7.85$ & $207.29 \pm 81.02$ & $0.0001^{\mathrm{a}, \mathrm{b}, \mathrm{c}, * * *}$ \\
\hline Weight (kg) & $63.49 \pm 8.87$ & $71.96 \pm 7.54$ & $75.94 \pm 8.64$ & $0.0001^{\mathrm{a}, \mathrm{b}, \mathrm{c}, * * *}$ \\
\hline Height $(\mathrm{cm})$ & $158.53 \pm 9.33$ & $156.89 \pm 8.71$ & $158.02 \pm 8.36$ & $0.0884^{\mathrm{a}, \mathrm{b}, \mathrm{c}, \mathrm{ns}}$ \\
\hline BMI $\left(\mathrm{kg} / \mathrm{m}^{2}\right)$ & $25.18 \pm 1.86$ & $28.57 \pm 2.31$ & $30.35 \pm 1.77$ & $0.0001^{\mathrm{a}, \mathrm{b}, \mathrm{c}, * * *}$ \\
\hline $\mathrm{WC}(\mathrm{cm})$ & $76.38 \pm 7.52$ & $94.13 \pm 7.08$ & $103.13 \pm 11.35$ & $0.0001^{\mathrm{a}, \mathrm{b}, \mathrm{c}, * * *}$ \\
\hline $\mathrm{HC}(\mathrm{cm})$ & $90.56 \pm 7.14$ & $105.57 \pm 10.22$ & $104.92 \pm 12.67$ & $0.0001^{\mathrm{a}, \mathrm{b}, \mathrm{c}, * * *}$ \\
\hline W/H Ratio & $0.85 \pm 0.08$ & $0.90 \pm 0.06$ & $0.99 \pm 0.05$ & $0.0001^{\mathrm{a}, \mathrm{b}, \mathrm{c}, * * *}$ \\
\hline Duration of HTN (y) & - & $4.70 \pm 4.11$ & $7.91 \pm 4.52$ & - \\
\hline Duration of diabetes $(y)$ & - & - & $5.72 \pm 4.32$ & - \\
\hline
\end{tabular}

Statistical analysis of data was carried by one-way ANOVA followed by Tukey's Multiple Range Test. The values are mean \pm SD for each group, ${ }^{a}$ normal $\mathrm{v} / \mathrm{s}$ essential hypertension, bnormal $\mathrm{v} / \mathrm{s}$ essential hypertension with new onset of diabetes, cessential hypertension $\mathrm{v} / \mathrm{s}$ essential hypertension with new onset of diabetes, ${ }^{* * *}$ Highly significant, ${ }^{* *}$ Moderate significant, ns Non significant 
The mutual comparison of the demographic details of normal, essential hypertension and essential hypertension with new onset of diabetes groups revealed that the age was moderately significant for normal v/s essential hypertension with new onset of diabetes comparison only $(\mathrm{p}<0.01)$ and was non-significant for another group comparison ( $p>0.05)$. Likely, height was also non-significant when compared among these three groups $(p>0.05)$. However, all other anthropometric and clinical parameters were highly significant among the three comparison groups $(\mathrm{p}<0.0001)$.

In socio-demographic data comparison (table 4), in all groups, smokers and drinkers were lesser in number than non-smokers and non-drinkers. Similarly, vegetarian individuals were higher in number as compared to non-vegetarian among disease groups. The majority of the patients were belonging to the illiterate and nonworking category having a sedentary lifestyle in both the groups. The lower number of patients was having a family history profile.

Pattern of anti-hypertensive drug therapy among the essential hypertension patients

Out of total 270 essential hypertension patients, monotherapy was prescribed to 109 (40.37\%) patients while combination drug therapy was prescribed to 161 (59.63\%) patients (fig. 5).

Table 4: The socio-demographic details of the populations under study

\begin{tabular}{|c|c|c|c|}
\hline Parameters & Normotensive n (\%) & Essential hypertension n (\%) & Essential hypertension with new onset of diabetes n (\%) \\
\hline \multicolumn{4}{|l|}{ Gender } \\
\hline Male & $150(55.5)$ & $95(35.1)$ & $80(33.4)$ \\
\hline Female & $120(44.5)$ & $175(72.9)$ & $160(66.6)$ \\
\hline \multicolumn{4}{|l|}{ Smoking } \\
\hline Smoker & $108(40)$ & $60(22.2)$ & $20(8.4)$ \\
\hline Non smoker & $162(60)$ & $210(77.7)$ & $220(91.6)$ \\
\hline \multicolumn{4}{|l|}{ Drinking } \\
\hline Drinker & $60(22.3)$ & $50(18.5)$ & $20(8.4)$ \\
\hline Non drinker & $210(77.7)$ & $220(81.4)$ & $220(91.6)$ \\
\hline \multicolumn{4}{|l|}{ Food habits } \\
\hline Vegetarian & $126(46.7)$ & $170(62.9)$ & 165 (68.7) \\
\hline Non-vegetarian & $144(53.3)$ & $100(37.1)$ & 75 (31.2) \\
\hline \multicolumn{4}{|l|}{ Occupation } \\
\hline Own business & $72(26.6)$ & $40(14.8)$ & $35(14.5)$ \\
\hline Farming & 78 (28.8) & $25(9.2)$ & $40(16.6)$ \\
\hline Non-workers & $36(13.3)$ & $140(51.8)$ & $150(62.5)$ \\
\hline Workers & $54(20)$ & $55(20.3)$ & $15(6.25)$ \\
\hline Students & $30(11.11)$ & 0 & 0 \\
\hline \multicolumn{4}{|l|}{ Education } \\
\hline Illiterate & $96(35.5)$ & $125(46.2)$ & $100(41.6)$ \\
\hline Primary & $36(13.3)$ & $50(18.5)$ & $55(22.9)$ \\
\hline Secondary & $54(20)$ & $55(20.3)$ & 45 (18.7) \\
\hline Higher education & $84(31.1)$ & $40(14.8)$ & $40(16.6)$ \\
\hline \multicolumn{4}{|l|}{ Family History } \\
\hline Yes & $90(33.3)$ & $55(20.3)$ & $85(35.4)$ \\
\hline No & $180(66.6)$ & $215(79.6)$ & $155(64.6)$ \\
\hline
\end{tabular}

$\mathrm{n}(\%)=$ number of total individuals (value in percentage)

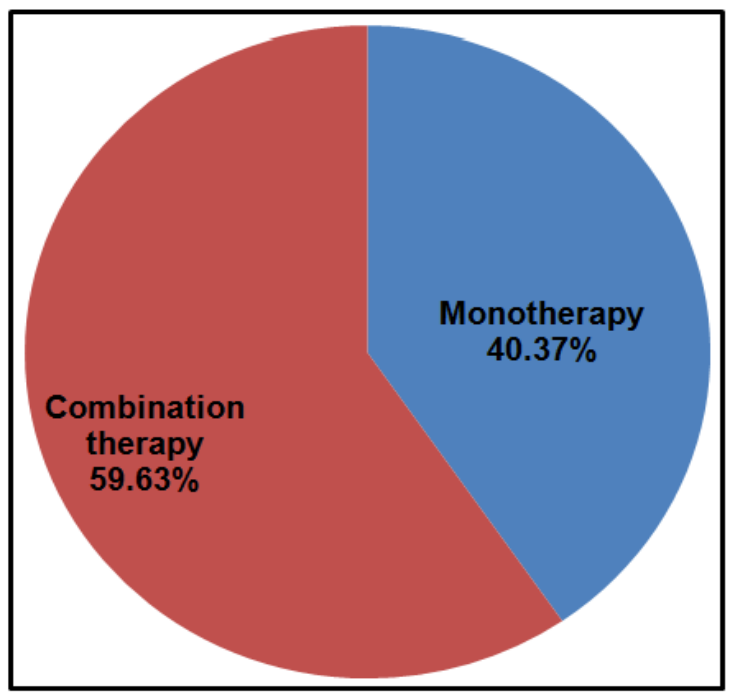

Fig. 5: Antihypertensive drug therapy prescription pattern among essential hypertension patients

Out of total 109 monotherapy patients, BB and diuretics were equally prescribed in $32(29.36 \%)$ patients followed by CCB in 45 $(41.28 \%)$ patients (table 5$)$.
The gender wise data showed that out of total 37 monotherapy male patients, BB (29.73\%) and a diuretic (29.73\%) were most prescribed drug therapy followed by CCBs (40.54\%). Out of total 
72 female patients, the almost same trend was observed for BB (29.17\%), diuretics (29.17\%) and CCBs (41.66\%) (fig. 6).
Surprisingly, ACEIs and ARBs were not prescribed to a single patient as monotherapy.

Table 5: Prescription pattern of monotherapy among the essential hypertensive patients

\begin{tabular}{llll}
\hline Monotherapy & Number of prescriptions & Total n (\%) \\
\cline { 2 - 3 } & Male $\mathbf{n}(\%)$ & Female n (\%) & $32(29.36)$ \\
BB & $11(29.73)$ & $21(29.17)$ & $32(29.36)$ \\
Diuretics & $11(29.73)$ & $21(29.17)$ & $45(41.28)$ \\
CCB & $15(40.54)$ & $30(41.66)$ & $109(100.00)$ \\
Total & $37(100.00)$ & $72(100.00)$ & 109 \\
\hline
\end{tabular}

$\mathrm{n}(\%)=$ number of total individuals (value in percentage)

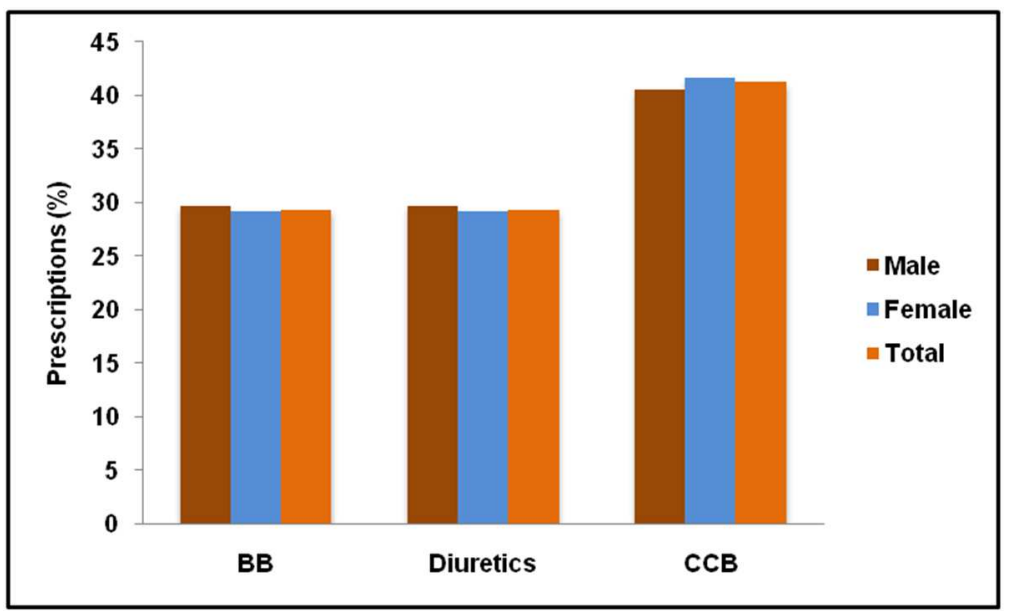

Fig. 6: Gender wise distribution of anti-hypertensive drugs as monotherapy

Among total 240 Essential hypertension with new onset of diabetes patients, $80(33.33 \%)$ were male and $160(66.67 \%)$ were females. Mono drug therapy was prescribed to $78(32.50 \%)$ patients; whereas combination therapy was given to $162(67.50 \%)$ patients (fig. 7).

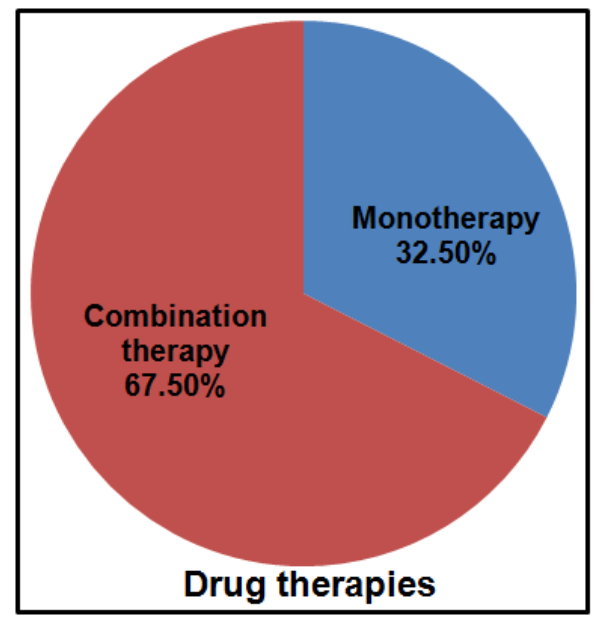

Fig. 7: Antihypertensive drug therapy prescription pattern among essential hypertension with new onset of diabetes patients

\section{DISCUSSION}

Hypertension and diabetes are prevailing throughout the world, leading to the risk of other cardiovascular diseases like stroke, heart failure, kidney failure and are the major cause of mortality [14].
Hypertension and diabetes are interrelated diseases, the combination of which becomes lethal to the mankind. Not only hypertension is considered as one of the risk factors for developing diabetes but also antihypertensive therapy also been found associated with new onset of diabetes in essential hypertension patients [10]. Therefore, a high prevalence of hypertension is dangerous in either way and poses health problems in the mankind.

In India, the prevalence of hypertension and diabetes is increasing at an alarming rate with the development of the country. Availability of an exact data of a particular area about the prevalence of hypertension, diabetes and other related diseases may help the healthcare system to serve in an efficient way and combat the diseases effectively. Therefore, in the present study, we tried to assess the prevalence of essential hypertension, the prescription pattern of antihypertensive drugs, and risk factors for new onset of diabetes in hypertensive patients.

From the retrospective study, we found a very high prevalence of essential hypertension $(41.21 \%)$ and diabetes $(15.87 \%)$ in the overall population (table 1) which is slightly higher than the previous study conducted in the same population area by Gupta et al., 2011 [12]. The gender wise data revealed that the prevalence of hypertension was more in male $(21.59 \%)$ than females $(19.61 \%)$. Similarly, the prevalence of diabetes was more in males $(9.06 \%)$ than females (6.81\%). While the prevalence of essential hypertension with new onset of diabetes patients showed that the prevalence of new onset of diabetes in hypertensive female patients $(7.26 \%)$ was more than male patients $(4.57 \%)$. The Antihypertensive therapy prescription pattern showed that monotherapy was prescribed to about $59.85 \%$ patients and a combination therapy to $40.15 \%$ patients during the year 2009 to 2013 (table 2). Among which, BBs were the most prescribed drugs followed by CCBs and ARBs.

In prospective study, mutual comparison of different anthropometric parameters among normal, essential hypertension 
and essential hypertension with new onset of diabetes group patients (table 3) suggested that the comparative p-value for age and height parameters were non-significant $(p>0.05)$ which indicated that these two parameters were not the risk factor for essential hypertension and new onset of diabetes. But other parameters such as SBP, DBP, FBG level, weight, BMI, WC, HC and W/H ratio were differing significantly which clearly indicated these parameters as the risk factors for essential hypertension which further may be associated with new onset of diabetes. From the socio-demographic data, it is evident that illiterate people living in sedentary conditions, with elevated BP and family history of diabetes were at higher risk of hypertension and further diabetes $[15,16]$.

A significant shift in the pattern of antihypertensive drug therapy from monotherapy to a combination therapy was observed in the prospective study (fig. 5) when it was compared with that from the retrospective study (table 2). Over these years, more patients were shifted to combination drug therapy $(59.63 \%)$ and a reduction in monotherapy patients (40.37\%) was observed. The same scenario of the antihypertensive therapy prescription pattern was observed for essential hypertension with new onset of diabetes patients. This indicated the severity of the diseases and their pace with which these are spreading. CCBs were most prescribed drugs in the prospective study followed by BBs and diuretics, but surprisingly, ACEIs and ARBs were not prescribed to even a single patient. Therefore, from our data, it was found that the prescription pattern of the antihypertensive therapy shifted from monotherapy to combination therapy from 2009-2013 data to 2016 data which suggest the severity of the disease.

\section{CONCLUSION}

Our study suggests that essential hypertension is the most prevalent disease in the rural population of Haryana in both males and females. However, essential hypertension with new onset of diabetes was more prevalent in the female population. The severity of the disease increased from 2009 to 2016 which resulted in the shift of the prescription pattern of the antihypertensive from monotherapy to combination therapy in the majority of the patients. Different anthropometric parameters are the indicator of risk factors associated with essential hypertension and new onset of diabetes in these patients. Person's lifestyle pattern also indicated the risk factor for essential hypertension and new onset of diabetes. An illiterate person living in sedentary lifestyle is at most risk.

\section{ACKNOWLEDGEMENT}

We would like to acknowledge the doctors and patients of the M. M. College of Pharmacy, M. M. Institute of Medical Science and Research, Mullana and Department of Biotechnology, IIT Roorkee for providing all the facilities and cooperation during collection of data.

\section{AUTHORS CONTRIBUTIONS}

The corresponding author (Dr. Sumeet Gupta) is the principal author and guided the project, first author (Vikas Jhawat) carried out the complete experimental work, Dr. Bimal Kumar Agarwal helped in identification, selection and recruitment of appropriate patients and collection of samples and Dr. Partha Roy and Dr. Vipin Saini helped in the study protocol designing and editing and further analysis.

\section{CONFLICT OF INTERESTS}

Declared none

\section{REFERENCES}

1. Mohan V. Seedat YK, Pradeepa R. The rising burden of diabetes and hypertension in southeast asian and african regions: need for effective strategies for prevention and control in primary health care settings. Int J Hypertens 2013;1-14. http://dx.doi.org/10.1155/2013/409083

2. Swami SS, Swami SC, Patil VW, Kanhere AM. Hypertension and diabetes in India: a review. Int J Clin Biochem Res 2015;2:54-8.

3. Anchala $\mathrm{R}$, Kannuri NK, Pant $\mathrm{H}$, Khan $\mathrm{H}$, Franco $\mathrm{OH}$, Angelantonio ED, et al. Hypertension in India: a systematic review and meta-analysis of prevalence, awareness, and control of hypertension. J Hypertens 2014;32:1170-7.

4. Kearney PM, Whelton M, Reynolds K, Muntner P, Whelton PK, He J. Global burden of hypertension: analysis of worldwide data. Lancet 2005;365:217-23.

5. Cheung BMY, Li C. Diabetes and hypertension: Is there a common metabolic pathway? Curr Atheroscler Rep 2012;14:160-6.

6. Kannel WB, Wilson PW, Zhang TJ. The epidemiology of impaired glucose tolerance and hypertension. Am Heart J 1991;121:1268-73.

7. Sahay BK: API-ICP guidelines on DM.J Assoc Physicians India 2007;55:1-50.

8. Sowers JR, Epstein M, Frohlich ED. Diabetes, hypertension, and cardiovascular disease: an update. J Hypertens 2001;37:53-9.

9. Shah A, Afzal M. Prevalence of diabetes and hypertension and association with various risk factors among different Muslim populations of Manipur, India. J Diabetes Metab Disord 2013;12:52.

10. Gupta S, Jhawat V. Induction of type 2 diabetes mellitus with antihypertensive therapy: is there any role of alpha-adducin, ACE, and IRS-1 Gene? Value Health Regional Issues 2017;12c:90-8.

11. Bakris GL. Maximizing cardiorenal benefit in the management of hypertension: achieve blood pressure goals. J Clin Hypertens 1999;1:141-7.

12. Gupta S, Agrawal BK, Sehajpal PK, Goel RK. Prevalence and predictors of essential hypertension in the rural population of Haryana, India: a hospital-based study. J Rural Trop Public Health 2011;10:29-34.

13. Gupta S, Chattopadhyaya I, Agrawal BK, Sehajpal PK, Goel RK. Correlation of renin-angiotensin system (RAS) candidate gene polymorphisms with response to Ramipril in patients with essential hypertension. J Postgrad Med 2015;61:21-6.

14. World Health Organization. A global brief on hypertension. World Health Day; 2013. p. 1-39.

15. Thilip KG, Prabhavathi K, Karthick N, Poornima KN, Saravanan A. Evaluation of pre-hypertension, hypertension and its associated factors among $1^{\text {st }}$ year medical students. Asian J Pharm Clin Res 2014;7:32-5.

16. Suhadi R, Linawati Y, Wulandari ET, Viriginia DM, Setiawan CH. The metabolic disorders and cardiovascular risk among lower socioeconomic subjects in yogyakarta-Indonesia. Asian J Pharm Clin Res 2017;10:367-2. 